\title{
Ocorrência de Pectobactérias em Tubérculos de Batata-Semente no Estado do Rio Grande do Sul
}

\author{
Samira O. M. EI Tassa \& Valmir Duarte \\ Departamento de Fitossanidade, Faculdade de Agronomia, UFRGS, Cx. Postal 15100, CEP 90001-970, Porto Alegre, \\ Rio Grande do Sul, fax: (51) 3316-6016, e-mail: valmir@ufrgs.br
}

(Aceito para publicação em 17/06/2004)

Autor para correspondência: Valmir Duarte

EL TASSA, S.O.M. \& DUARTE, V. Ocorrência de pectobactérias em tubérculos de batata-semente no Estado do Rio Grande do Sul. Fitopatologia Brasileira 29:620-625. 2004.

\section{RESUMO}

Tubérculos de batata (Solanum tuberosum)-semente, prébásica, básica, registrada e certificada, de oito cultivares, oriundos de 21 lavouras localizadas nos municípios de Vacaria, Canguçu, Piratini e Ibiraiaras, no Rio Grande do Sul, foram coletados nos meses de maio a agosto de 2002. Cada tubérculo foi lavado em água corrente, deixado secar à temperatura ambiente, perfurado com palitos em dez lenticelas, coberto com fina camada de óleo de soja, colocado individualmente em cima de folha de papel toalha umedecida dentro de saco plástico transparente e incubado a $23{ }^{\circ} \mathrm{C}$ por quatro dias. A incidência de podridão mole a partir das lenticelas variou de $20-100 \%$ entre as cultivares. Pectobacterium sp. foi constatada em tubérculos das 21 lavouras. Duzentos e vinte e três isolados de Pectobacterium sp. foram obtidos em meio CPG, a partir das lenticelas com podridão mole, e identificados por testes bioquímicos, fisiológicos e PCR em nível de subespécie. Cento e dezenove isolados foram identificados como P. carotovorum subsp. brasiliensis e e 96 com o P. carotovorum subsp. carotovorum. Oito isolados não se enquadraram na classificação bioquímica. Pectobacterium carotovorum subspp. estavam presentes em tubérculos de batata-semente, independente da cultivar, classe ou município de origem. Pectobacterium carotovorum subsp. atrosepticum, a principal responsável por causar canela preta em batata em outros países, não foi detectada.

Palavras-chave adicionais: Pectobacterium carotovorum subsp. carotovorum, Pectobacterium carotovorum subsp. brasiliensis, Pectobacterium carotovorum subsp. atrosepticum, Solanum tuberosum.

\section{ABSTRACT}

Ocurrence of pectobacteria in potato seed tubers in Rio Grande do Sul

Seed potato (Solanum tuberosum) tubers from eight cultivars of 21 fields in Vacaria, Canguçu, Piratini and Ibiraiaras, all in the state of Rio Grande do Sul, were harvested from May to August of 2002. Each tuber was washed in running water, left to dry at environment temperature $\left(23{ }^{\circ} \mathrm{C}\right)$, stabbed with toothpicks in ten lenticels, covered with a thin layer of soybean oil, put individually on a wet paper towel inside a transparent plastic bag and incubated at 23 ${ }^{\circ} \mathrm{C}$ for four days. The incidence of soft rot in lenticels ranged from 20 $100 \%$ among the cultivars. Pectobacterium sp. was found in tubers from every field. Two hundred and twenty three isolates of Pectobacterium sp. were obtained on CPG medium, from lenticels showing soft rot symptoms, and identified by biochemical and physiological tests and PCR, at subspecies levels. One hundred and nineteen and 96 strains were identified as $P$. carotovorum subsp. brasiliensis and $P$. carotovorum subsp. carotovorum, respectively. Eight strains did not fit in the biochemical classification. $P$. carotovorum subspp. were present in seed tubers potato, regardless of the cultivar, seed class or county. Pectobacterium carotovorum subsp. atrosepticum, the major agent associated with blackleg on potato in other countries, was not found.

\section{INTRODUÇÃO}

As maiores áreas de plantio de batata (Solanum tuberosum L.), no Brasil, localizam-se no Rio Grande do Sul, no entanto, a produtividade média é bastante baixa ( $9 \mathrm{t} / \mathrm{ha}$ ) quando comparada a de outros Estados que chega a quase 30 t/ha (IBGE, 2003). Este baixo rendimento deve-se, em grande parte, pelo uso de batata-semente de baixa qualidade fitossanitária. A batata é uma cultura que se propaga por tubérculos, embora existam "sementes verdadeiras". Esta forma de propagação favorece a disseminação de vários patógenos, entre eles as pectobactérias, cuja principal característica é a produção de enzimas pectolíticas em grande quantidade (Colmer \& Keen, 1986; Pirhonen et al., 1991;
Salmond, 1994) que ocasiona a rápida maceração dos tubérculos (podridão mole) ou dos tecidos da haste (canela preta e podridão da haste). Em batata, Pectobacterium carotovorum subsp. atrosepticum (van Hall) Hauben et al., P. carotovorum subsp. carotovorum (Jones) Hauben et al. e P. chrysanthemi (Bulkholder et al.) Brenner et al. emend. Hauben et al. são predominantes (Pérombelon \& Kelman, 1987). Pectobacterium carotovorum subsp. atrosepticum é considerada a única capaz de causar sintomas típicos de canela preta a partir de tubérculos infetados (Pérombelon \& Kelman, 1980), mas qualquer uma das três pode estar presente no tecido infetado, dependendo principalmente da temperatura. No Rio Grande do Sul, a coleta de plantas com sintomas de canela preta resultou na obtenção de 408 isolados (Oliveira et al., 
Ocorrência de pectobactérias em tubérculos de batata-semente no...

2003). Dentre estes, 55, 42 e $1 \%$ foram identificados com base em características bioquímicas como $P$. carotovorum subsp. atrosepticum, $P$. carotovorum subsp. carotovorum e $P$. chrysanthemi, respectivamente, e $2 \%$ apresentaram características que não corresponderam ao padrão bioquímico e fisiológico de nenhuma espécie ou subespécie. Entretanto, oligonucleotídeos iniciadores específicos para $P$. carotovorum subsp. atrosepticum (De Boer \& Ward, 1995; Fréchon et al., 1998) amplificaram o DNA da estirpe controle de $P$. carotovorum subsp. atrosepticum, mas não das estirpes identificadas como $P$. carotovorum subsp. atrosepticum (Oliveira et al., 2003). Estudos posteriores mostraram que as estirpes brasileiras, identificadas como $P$. carotovorum subsp. atrosepticum, apresentam perfis genético, bioquímico, fisiológico e sorológico diferentes, gerando a proposta de uma nova subespécie: $P$. carotovorum subsp. brasiliensis Duarte et al. (Duarte et al., no prelo). Dessa forma, o sintoma de canela preta presente em plantas de batata cultivadas no Rio Grande do Sul pode não ser causado por $P$. carotovorum subsp. atrosepticum, mas por outras espécies e/ou subespécies. Além disso, assim como observado para canela preta em batata no Rio Grande do Sul (Oliveira et al., 2003; Duarte et al., 2004), podem existir outras subespécies, ou mesmo espécies de Pectobacterium, ainda não identificadas, envolvidas na podridão mole de tubérculos, podendo resultar em canela preta, além de P. carotovorum subsp. atrosepticum. Este novo fato pode ter implicações epidemiológicas importantes, ainda não conhecidas, podendo refletir nas estratégias de controle a serem aplicadas. Dessa forma, este trabalho teve o objetivo de identificar e verificar a incidência de espécies e subespécies de pectobactérias presentes em tubérculos de batata-semente, produzidos no Rio Grande do Sul, visto a importância deste material na disseminação de patógenos.

\section{MATERIAL E MÉTODOS}

\section{Amostragem e incubação}

As amostras de tubérculos de batata-semente foram obtidas após a colheita da safra outono/inverno de 2002, nos meses de maio a agosto, em 21 lavouras nos municípios de Canguçu, Ibiraiaras, Piratini e Vacaria. A amostra constou de 30 tubérculos, por cultivar (Asterix, Baraka, Baronesa, Bintje H., Elvira, Macaca, Monalisa, Pérola), das classes pré-básica, básica, registrada e certificada, coletados aleatoriamente, acondicionada em sacos plásticos e identificada. Cada tubérculo foi lavado em água corrente, deixado secar à temperatura ambiente $\left(23{ }^{\circ} \mathrm{C}\right)$, perfurado com palitos em dez lenticelas, mergulhado em óleo de soja, deixado escorrer, colocado individualmente em cima de folha de papel toalha umedecida dentro de saco plástico transparente e incubado a $23{ }^{\circ} \mathrm{C}$ por quatro dias. A avaliação constou da contagem de tubérculos macerados, isolamento e identificação de pectobactérias.

\section{Isolamento de pectobactérias}

Palitos de madeira esterilizados foram encostados nas extremidades das lesões dos tubérculos macerados e introduzidos em frutos de pimentão verde (Capsicum annuum L.), previamente desinfestados (álcool 70\%, $30 \mathrm{~s}$; $\mathrm{NaOCl} 1 \%$, $30 \mathrm{~s}$; e lavado com água destilada esterilizada (ADE) (Takatsu et al., 1981). Os pimentões foram colocados em bandeja, contendo papel umedecido no fundo, coberta com saco plástico e incubados a $28^{\circ} \mathrm{C}$ por $24-48 \mathrm{~h}$. Palitos submersos em ADE e introduzidos nos pimentões foram o controle negativo. Após, a epiderme do fruto no local da lesão foi retirada, a alça de platina encostada no tecido de transição entre a parte sintomática e a sadia, riscada em diluições sucessivas em meio CPG (casamino ácido, 1; peptona, 10; glicose, 10; ágar, 18 g/l) (De Boer \& Kelman, 2001) e incubada a $28^{\circ} \mathrm{C}$ por $24 \mathrm{~h}$. Colônias de coloração creme, com bordos irregulares, opacas, com característica de "vidro quebrado" (Duarte \& El Tassa, 2003) quando observadas ao microscópio estereoscópico com iluminação oblíqua, foram repicadas para meio nutriente ágar (Merck, Darmstadt) para aumento do inóculo. Os isolados foram armazenados em $\mathrm{ADE}$ a $4{ }^{\circ} \mathrm{C}$ e glicerol-água (15:85) a $-20{ }^{\circ} \mathrm{C}$.

\section{Identificação bioquímica e fisiológica}

Os isolados obtidos foram identificados através dos seguintes testes: gram, atividade pectolítica em batata, oxidase, catalase, fermentação de glicose (oxidação/ fermentação), crescimento a $37{ }^{\circ} \mathrm{C}$, utilização de $\alpha$-metil glicosídeo (estirpes positivas formam colônias com centro vermelho), sensibilidade à eritromicina, produção de substâncias redutoras de sacarose, produção de ácidos a partir de maltose $\mathrm{D}(+)$, lactose e sorbitol (Hyman et al., 1998; De Boer \& Kelman, 2001). As estirpes utilizadas como referência foram: P. carotovorum subsp. atrosepticum (Pca 31), cedida por S. H. De Boer (CFIA, Canadá), P. carotovorum subsp. carotovorum (IBSBF 1442), P. chrysanthemi (IBSBF 920), P. carotovorum subsp. betavasculorum (Thomson et al.) Hauben et al. (IBSBF 787) e P. carotovorum subsp. wasabiae (Goto \& Matsumoto) Hauben et al. (IBSBF 803) cedidas por J. Rodrigues Neto (Instituto Biológico, SP) e P. carotovorum subsp. brasiliensis, estirpes Pcbr 8 (ATCC BAA-416), Pcbr $212^{\mathrm{T}}$ (ATCC BAA-417), Pcbr 213 (ATCC BAA-418) e Pcbr 371 (ATCC BAA-419).

A capacidade dos isolados em utilizar diferentes açúcares foi testada em placas de microtitulação (96 amostras/ placa) (Silveira et al., 2002; Oliveira et al., 2003) contendo $150 \mu 1$ de meio de cultura (peptona, $10 \mathrm{~g}$; púrpura de bromocresol 1,5\%, 0,7 ml; ágar, 0,3 g; açúcar 10\%, 100ml/1, pH 6,8) (Dickey \& Kelman, 1988). Culturas com 24-48 h de crescimento foram transferidas para o meio com o auxílio de um palito de madeira esterilizado, e incubadas a $28{ }^{\circ} \mathrm{C}$ por $48 \mathrm{~h}$. A mudança de cor de púrpura para amarela foi considerada positiva. Os testes foram conduzidos pelo menos duas vezes.

\section{Identificação pelo sistema BIOLOG}

Isolados bacterianos, cultivados em meio nutriente ágar a $28^{\circ} \mathrm{C}$ por $24 \mathrm{~h}$, foram transferidos para meio BUGM (Biolog Universal Growth Medium) e incubados nas mesmas 
condições. Posteriormente, foi feita uma suspensão bacteriana em solução tampão salina $(\mathrm{NaCl} 0,15 \%)$. A suspensão (150 $\mu 1)$ foi adicionada em cada um dos 96 orifícios das placas do sistema BIOLOG gram-negativa (Biolog, Inc., Hayward, CA, EUA), contendo 95 diferentes fontes de carbono, incubadas por $24 \mathrm{~h}$ a $28{ }^{\circ} \mathrm{C}$, e a densidade óptica (405 nm) obtida em leitor de placas de microtitulação (Titertek Multiskan Plus). A análise dos resultados e a identificação dos isolados foram realizadas pelo programa MicroLog (Biolog, Inc., Hayward, CA, EUA).

\section{Identificação por PCR}

Culturas bacterianas, com $24-48 \mathrm{~h}$, foram transferidas para $250 \mu \mathrm{l}$ de tampão de extração de DNA (100mM tris$\mathrm{HCl} \mathrm{pH} 8,0 ; 25 \mathrm{mM}$ EDTA; $1 \%$ SDS e $5 \mu \mathrm{g}$ de proteinase $\mathrm{K}$ ), com o auxílio de um palito de dente e incubadas por $3 \mathrm{~h}$ a 56 ${ }^{\circ} \mathrm{C}$ em banho-maria. Posteriormente, $250 \mu \mathrm{l}$ de acetato de amônio 7,5 $\mathrm{M}$ foi adicionado, misturado e centrifugado a $14.000 \mathrm{~g}$ por $10 \mathrm{~min}$. O sobrenadante foi transferido para outro tubo, um volume de isopropanol foi adicionado e incubado por cerca de $16 \mathrm{~h} \mathrm{a}-20^{\circ} \mathrm{C}$. O precipitado foi obtido através de centrifugação por $25 \mathrm{~min}$ a $14.000 \mathrm{~g}$ a $4^{\circ} \mathrm{C}$, lavado com etanol 70\%, seco, dissolvido em $50 \mu$ l de água ultra pura e armazenado a $-20{ }^{\circ} \mathrm{C}$ (De Boer \& Ward, 1995).

O DNA extraído dos isolados foi submetido à Reação em Cadeia da Polimerase (PCR), utilizando os seguintes oligonucleotídeos iniciadores (5' - 3'): ECA1f(CGGCATCAT AAAAACACG)/ECA2r(GCACACTTCATCCAGCGA) (De Boer \& Ward, 1995) que produzem um fragmento de $690 \mathrm{pb}$, específico para $P$. carotovorum subsp. atrosepticum; $1491 \mathrm{f}$ (GAAGTCGTAACAAGGTA)/L1RA (CAAGGCATCCACC GT)/L1RG (CAGGGCATCCACCGT) da região espaçadora intergênica (IGS) diferenciando P. carotovorum (fragmentos $\mathrm{de} \approx 510 \mathrm{pb} \mathrm{e} \approx 550 \mathrm{pb}$ ) de $P$. chrysanthemi (um fragmento adicional de $480 \mathrm{pb}$ ) (Fessehaie et al., 2002); e Br1f(GCGTG CCGGGTTTATGACCT)/L1RA/L1RG que produzem um fragmento de $322 \mathrm{pb}$ e diferencia $P$. carotovorum subsp. brasiliensis e algumas estirpes de $P$. carotovorum subsp. carotovorum das demais pectobactérias (Duarte et al., 2004).

As reações foram feitas em um volume final de $10 \mu \mathrm{l}$, sendo que com ECA1f/ECA1r $\left(94{ }^{\circ} \mathrm{C} / 5 \mathrm{~min}\left(94{ }^{\circ} \mathrm{C} / 30 \mathrm{~s}, 65\right.\right.$ $\left.{ }^{\circ} \mathrm{C} / 45 \mathrm{~s}, 72{ }^{\circ} \mathrm{C} / 45 \mathrm{~s}\right) 25 \mathrm{X}, 72{ }^{\circ} \mathrm{C} / 5 \mathrm{~min}$ ) foi usado $1 \mu \mathrm{M}$ de cada oligonucleotídeo iniciador; tampão de reação $(10 \mathrm{mM}$

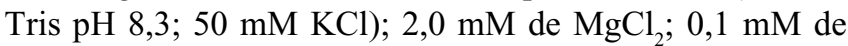
cada dNTP (Invitrogen); 0,5 unidades de Taq DNA polimerase (Invitrogen) e aproximadamente $100 \mathrm{ng}$ de DNA (De Boer \& Ward, 1995). Para PCR da região IGS $\left(94^{\circ} \mathrm{C} / 2 \mathrm{~min}\left(94^{\circ} \mathrm{C} /\right.\right.$ $\left.\left.45 \mathrm{~s}, 66^{\circ} \mathrm{C} / 45 \mathrm{~s}, 72{ }^{\circ} \mathrm{C} / 1,5 \mathrm{~min}\right) 30 \mathrm{X}, 72^{\circ} \mathrm{C} / 10 \mathrm{~min}\right)$ foi usado $1 \mu \mathrm{M}$ de cada oligonucleotídeo iniciador, tampão de reação (10 mM Tris $\mathrm{pH} 8,3 ; 50 \mathrm{mM} \mathrm{KCl}$ ); 2,5 mM de $\mathrm{MgCl}_{2}$; 0,1 mM de cada dNTP (Invitrogen); 0,5 unidades de Taq DNA polimerase (Invitrogen) e aproximadamente $100 \mathrm{ng}$ de DNA (Fessehaie et al., 2002). A PCR contendo Br1f/L1RA/L1RG teve as mesmas condições da PCR da região IGS com as seguintes alterações: foi usado $1 \mu \mathrm{M}$ do primeiro oligonucleotídeo iniciador e $0,5 \mu \mathrm{M}$ dos outros dois e 2,0
$\mathrm{mM}$ de $\mathrm{MgCl}_{2}$ (Duarte et al., 2004)

Os produtos das amplificações foram separados por eletroforese em gel de agarose 1,2\%, corado com brometo de etídeo, visualizado sob luz ultra-violeta e fotografado através do sistema de análise de gel computadorizado (Kodak Digital Science 1D).

\section{RESULTADOS E DISCUSSÃO}

A incidência de podridão mole associada a bactérias pectolíticas na batata-semente das cultivares avaliadas variou de 20 a $100 \%$ (Tabela 1 ). A presença de $P$. carotovorum subspp. foi constatada em todas as amostras, independente da cultivar, classe ou município de origem. Este fato ressalta a importância dos tubérculos de batata-semente como principal fonte de inóculo das pectobactérias (Pérombelon \& Kelman, 1980). As bactérias sobrevivem na forma latente nas lenticelas e ferimentos suberizados ou nos tecidos vasculares de tubérculos que aparentemente estão livres do patógeno quando são colhidos. Quando as condições favorecem a multiplicação do patógeno e a produção de enzimas pectolíticas, o tubérculo apodrece e a bactéria se dissemina (Elphinstone, 1993). No entanto, a presença de pectobactérias em tubérculos-semente de diferentes classes, principalmente pré-básica, pode ser um indicativo da persistência destas bactérias no solo e/ou na água de irrigação. As sementes prébásicas são as de mais alta qualidade fitossanitária e, na maioria das vezes, são oriundas de cultura de tecidos. Pectobactérias não foram isoladas de alguns tubérculos com podridão mole. Este fato pode ser devido à presença de outras bactérias pectolíticas (Bacillus sp., Pseudomonas sp. e/ou outras) que poderiam estar causando o mesmo sintoma (Campos et al., 1982), mas sua identificação não foi objetivo do presente estudo. Outra razão poderia ser a baixa seletividade do meio de cultura CPG. Embora o meio de cultura CVP (cristal-violeta-pectato) (Cuppels \& Kelman, 1974) seja considerado mais eficiente, permitindo a formação de cavidades na superfície, para o isolamento de pectobactérias, esta eficiência depende do tipo de polipectato (Pierce \& McCain, 1992). O polipectato adequado (Bulmer, Slendid e Sunkist) é de difícil aquisição no Brasil e mesmo no exterior. No entanto, a utilização de fruto de pimentão verde como meio parcialmente seletivo (Takatsu et al., 1981) mostrou-se eficiente no processo de isolamento destas bactérias.

Colônias jovens de pectobactérias apresentaram aspecto de "vidro quebrado" (Duarte \& El Tassa, 2003) após 24-48 h de incubação a $28^{\circ} \mathrm{C}$. Esta característica da colônia, distingue as pectobactérias de pseudomonas e de outras bactérias comuns em solos (Kelman \& Dickey, 1989).

Duzentos e vinte e três isolados foram obtidos de tubérculos de batata-semente (Tabela 1). Dentre estes, 119 foram identificados como $P$. carotovorum subsp. brasiliensis e 96 como $P$. carotovorum subsp. carotovorum (Tabela 1). Oito isolados apresentaram características que não corresponderam a nenhuma espécie ou subespécie, não sendo possível identificá-los. Pectobacterium carotovorum subsp. 
Ocorrência de pectobactérias em tubérculos de batata-semente no...

TABELA 1 - Incidência de bactérias pectolíticas e Pectobacterium spp. em tubérculos de batata (Solanum tuberosum)-semente de oito cultivares em quatro municípios do Rio Grande do Sul e identificação bioquímica dos isolados

\begin{tabular}{|c|c|c|c|c|c|c|c|c|c|c|}
\hline \multirow{2}{*}{ Município } & \multirow{2}{*}{$\begin{array}{l}\text { Variedade } \\
\text { de batata }\end{array}$} & \multirow{2}{*}{ Classe $^{1}$} & \multirow{2}{*}{$\begin{array}{c}\text { Bacterias } \\
\text { pectolíticas (\%) }\end{array}$} & \multirow{2}{*}{$\begin{array}{c}\begin{array}{c}\text { Pectobacterium } \mathrm{sp} . \\
(\%)\end{array} \\
\end{array}$} & \multicolumn{6}{|c|}{ Pectobacterium spp. e subspp. ${ }^{2}$} \\
\hline & & & & & Pcbr & Pcc & Pca & Pch & ND & Total \\
\hline \multirow[t]{4}{*}{ Canguçu } & Baronesa & $\mathrm{R}$ & 73 & 40 & 10 & 01 & 0 & 0 & 0 & 11 \\
\hline & & $\mathrm{C}$ & 100 & 57 & 16 & 01 & 0 & 0 & 0 & 17 \\
\hline & Macaca & $\mathrm{R}$ & 83 & 13 & 03 & 01 & 0 & 0 & 0 & 04 \\
\hline & & $\mathrm{C}$ & 93 & 70 & 20 & 00 & 0 & 0 & 0 & 20 \\
\hline Média (\%) & & & 87 & 45 & - & - & 0 & 0 & - & - \\
\hline Total & & & - & - & 49 & 03 & 0 & 0 & 0 & 52 \\
\hline \multirow[t]{3}{*}{ Ibiraiaras } & Asterix & $\mathrm{C}$ & 20 & 17 & 0 & 02 & 0 & 0 & 03 & 05 \\
\hline & Elvira & $\mathrm{C}$ & 50 & 20 & 01 & 03 & 0 & 0 & 02 & 06 \\
\hline & Macaca & $\mathrm{C}$ & 93 & 13 & 01 & 03 & 0 & 0 & 0 & 04 \\
\hline Média (\%) & & & 54 & 17 & - & - & 0 & 0 & - & - \\
\hline Total & & & - & - & 02 & 08 & $\mathbf{0}$ & 0 & 05 & 15 \\
\hline \multirow[t]{7}{*}{ Piratini } & Asterix & B & 77 & 17 & 05 & 0 & 0 & 0 & 0 & 05 \\
\hline & Baronesa & B & 93 & 77 & 19 & 04 & 0 & 0 & 0 & 23 \\
\hline & & $\mathrm{R}$ & 100 & 37 & 03 & 07 & 0 & 0 & 0 & 10 \\
\hline & Macaca & B & 97 & 57 & 04 & 13 & 0 & 0 & 0 & 17 \\
\hline & & $\mathrm{R}$ & 83 & 37 & 02 & 09 & 0 & 0 & 0 & 11 \\
\hline & Monalisa & B & 77 & 53 & 05 & 11 & 0 & 0 & 0 & 16 \\
\hline & Pérola & $\mathrm{R}$ & 100 & 37 & 09 & 02 & 0 & 0 & 0 & 11 \\
\hline Média (\%) & & & 90 & 45 & - & - & 0 & 0 & - & - \\
\hline Total & & & - & - & 47 & 46 & 0 & 0 & 0 & 93 \\
\hline \multirow[t]{7}{*}{ Vacaria } & Asterix & PB & 63 & 40 & 03 & 09 & 0 & 0 & 0 & 12 \\
\hline & Baraka & PB & 100 & 12 & 03 & 02 & 0 & 0 & 0 & 05 \\
\hline & & B & 87 & 53 & 0 & 13 & 0 & 0 & 03 & 16 \\
\hline & Bintje H. & PB & 83 & 40 & 01 & 11 & 0 & 0 & 0 & 12 \\
\hline & Elvira & PB & 90 & 20 & 05 & 01 & 0 & 0 & 0 & 06 \\
\hline & Monalisa & PB & 73 & 7 & 09 & 01 & 0 & 0 & 0 & 10 \\
\hline & & B & 73 & 33 & 0 & 02 & 0 & 0 & 0 & 02 \\
\hline Média (\%) & & & 81 & 30 & - & - & 0 & 0 & - & - \\
\hline Total & & & - & - & 21 & 39 & 0 & 0 & 03 & 63 \\
\hline Total & & & & & 119 & 96 & 0 & $\mathbf{0}$ & 08 & 223 \\
\hline Porcentagem & & & & & 53 & 43 & 0 & 0 & 4 & 100 \\
\hline
\end{tabular}

${ }^{1} \mathrm{~PB}$, pré-básica; B, básica; R, registrada; C, certificada

${ }^{2}$ Pcbr, P. carotovorum subsp. brasiliensis; Pcc, P. carotovorum subsp. carotovorum; Pca, P. carotovorum subsp. atrosepticum; Pch, P. chrysanthemi; ND, não determinada

atrosepticum, considerada o principal agente causal da canela preta em outros países e $P$. chrysanthemi não foram detectadas.

Todos os isolados maceraram batata e apresentaram resultado positivo para $\mathrm{O} / \mathrm{F}$ e catalase e negativo para oxidase. Das estirpes de $P$. carotovorum subsp. carotovorum, $99 \%$ não produziram ácido a partir de maltose (Tabela 2), inclusive a estirpe de referência IBSBF 1442. Este resultado corrobora com os obtidos por Oliveira et al. (2003), onde 79\% das estirpes de $P$. carotovorum subsp. carotovorum foram negativas para este açúcar. Segundo Lelliot \& Dickey (1984), $21-79 \%$ das estirpes de $P$. carotovorum são positivas para maltose, mas estirpes de $P$. carotovorum subsp. carotovorum são negativas. No entanto, Hyman et al. (1998) mostraram que esta subespécie é positiva para maltose. Isto pode indicar uma diferença entre as estirpes brasileiras e de outros países. A produção de ácido de lactose e sorbitol (Tabela 2) por $P$. carotovorum subsp. carotovorum e $P$. carotovorum subsp. brasiliensis é consistente com a descrição das subespécies (Lelliot \& Dickey, 1984; Duarte et al., no prelo). As estirpes de $P$. carotovorum subsp. carotovorum não apresentaram colônias com centro vermelho em meio com $\alpha$-metil glicosídeo e cresceram a $37^{\circ} \mathrm{C}$, características que as diferenciam de $P$. carotovorum subsp. atrosepticum (De Boer \& Kelman, 2001).

Dos oito isolados que não foram identificados pelos testes bioquímicos, três não cresceram a $37^{\circ} \mathrm{C}$ e não formaram colônia com centro vermelho em meio com $\alpha$-metil glicosídeo, descartando a hipótese de ser $P$. carotovorum subsp. atrosepticum, bem como não produziram ácido de maltose, lactose e sorbitol. Pectobacterium carotovorum subsp. wasabiae (Goto \& Matsumoto) Hauben et al., responsável por causar descoloração interna de rizomas de Eutrema wasabi Maxim. (Goto \& Matsumoto, 1987), possui estas características e ainda não foi relatada em batata no Brasil. No entanto, o sistema BIOLOG identificou-os como $P$. carotovorum subsp. carotovorum (79\% de similaridade) e mostrou que usam melibiose e rafinose, diferentemente de $P$. carotovorum subsp. wasabiae (Goto \& Matsumoto, 1987).

Apesar do grande número de dados publicados sobre pectobactérias, referências sobre a ocorrência de formas intermediárias, nas condições brasileiras, ainda são muito escassas. Um levantamento de pectobactérias em diferentes hospedeiros e regiões do Brasil (Jabuonski et al., 1986) 


\section{S.O.M. El Tassa \& V. Duarte}

TABELA 2 - Resultados de testes bioquímicos e fisiológicos de 223 isolados de pectobactérias oriundos de batata (Solanum tuberosum)semente

\begin{tabular}{|c|c|c|c|c|c|c|c|c|c|}
\hline \multirow{3}{*}{ Identificação $^{1}$} & \multirow{3}{*}{$\begin{array}{l}\text { Número } \\
\text { de isolados }\end{array}$} & \multicolumn{8}{|c|}{ Testes bioquímicos e fisiológicos ( $\%$ positivos) } \\
\hline & & \multirow{2}{*}{$\mathbf{O} / \mathbf{F}^{2}$} & \multirow{2}{*}{$\begin{array}{c}\text { Crescimento } \\
\text { a } 37^{\circ} \mathrm{C}\end{array}$} & \multirow{2}{*}{$\begin{array}{c}\text { Sensibilidade } \\
\text { a eritromicina }\end{array}$} & \multirow{2}{*}{$\begin{array}{l}\text { Produção de } \\
\text { substâncias } \\
\text { redutoras de } \\
\text { sacarose }\end{array}$} & \multirow{2}{*}{$\begin{array}{c}\text { Utilização de } \\
\alpha \text {-metil } \\
\text { glicosídeo }\end{array}$} & \multicolumn{3}{|c|}{ Produção de ácido de } \\
\hline & & & & & & & Lactose & Maltose & Sorbitol \\
\hline Pcc & 95 & 100 & 100 & 0 & 0 & 0 & 100 & 1 & 0 \\
\hline Pcbr & 120 & 100 & 100 & 0 & 100 & 100 & 100 & 2,5 & 2,5 \\
\hline ND & 8 & 100 & 62,5 & 0 & 0 & 0 & 37,5 & 0 & 0 \\
\hline
\end{tabular}

${ }^{1}$ Pcc, Pectobacterium carotovorum subsp. carotovorum; Pcbr, P. carotovorum subsp. brasiliensis; ND, não determinada

${ }^{2} \mathrm{O} / \mathrm{F}$ - oxidação/fermentação

mostrou um grande número de estirpes formando ácido a partir de $\alpha$-metil glicosídeo e de substâncias redutoras a partir de sacarose, características de $P$. carotovorum subsp. atrosepticum, mas crescendo a $37{ }^{\circ} \mathrm{C}$. Estes isolados foram incluídos no grupo dos intermediários e não identificados. No entanto, as identificações anteriores não levaram em conta a grande homogeneidade genética, bioquímica e fisiológica destas estirpes, que culminou na proposição de $P$. carotovorum subsp. brasiliensis (Duarte et al., 2004). Da mesma forma, o relato da ocorrência em beterraba de uma pectobactéria com características bioquímicas de $P$. chrysanthemi e $P$. carotovorum subsp. atrosepticum, denominada $P$. carotovorum subsp. betavasculorum (Thomson et al., 1981), e com conteúdo de $\mathrm{G}+\mathrm{C}$ intermediária entre $P$. carotovorum subsp. carotovorum e $P$. chrysanthemi, é uma indicação de que as formas intermediárias possuem uma importância epidemiológica significativa e podem ser encontradas com maior freqüência a medida que levantamentos mais amplos sejam efetuados.

Todas as estirpes mostraram, através da PCR, a presença de dois fragmentos, citados como de $\approx 510 \mathrm{pb}$ e $\approx$ $550 \mathrm{pb}$ (Fessehaie et al., 2002), da região IGS, característicos da espécie $P$. carotovorum (Figura 1A). A utilização de oligonucleotídeos iniciadores para $P$. carotovorum subsp. brasiliensis (Figura 1B) e P. carotovorum subsp. atrosepticum (Figura 1C), confirmaram a identidade das estirpes de $P$. carotovorum subsp. brasiliensis e a ausência de $P$. carotovorum subsp. atrosepticum, respectivamente.

Baseado nos resultados encontrados, pode-se considerar que a utilização de batata-semente com pectobactérias, na forma latente, pelos produtores do Rio Grande do Sul, podem estar contribuindo para a grande incidência de canela preta (Oliveira et al., 2003) e podridão mole na produção de batata-consumo. A baixa qualidade fitossanitária dos tubérculos-semente, somado a outros fatores, pode explicar a menor produtividade do Rio Grande do Sul quando comparada a de outros Estados produtores (EPAGRI, 2002). Apesar de $P$. carotovorum subsp. atrosepticum ser considerada o agente causal dos sintomas típicos de canela preta, e a única capaz de causar tais sintomas a partir do tubérculo infetado (Pérombelom \& Kelman, 1980; De Boer, 2002), esta subespécie não foi detectada neste levantamento. Este fato reforça a hipótese de que outras espécies e/ou subespécies de pectobactérias podem causar o mesmo sintoma.

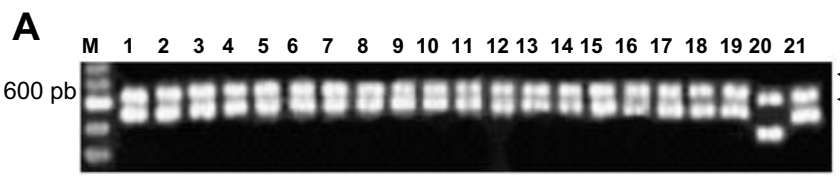

B

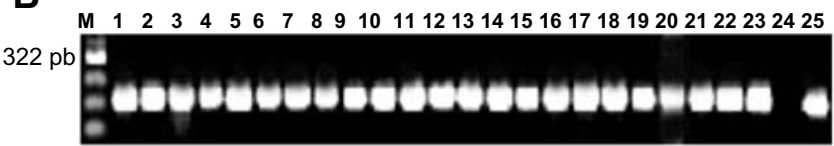

C

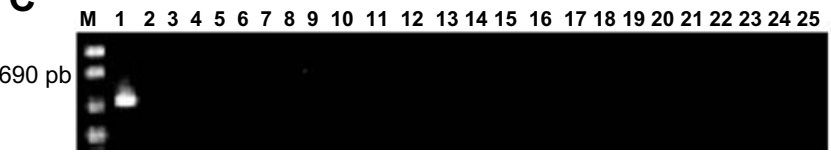

FIG. 1 - Amplificações de fragmentos de DNA de Pectobacterium spp. usando: A) oligonucleotídeos iniciadores da região IGS que separam $P$. carotovorum de $P$. chrysanthemi. M, marcador $100 \mathrm{pb}$; 1-15 e 17-19 P. carotovorum subsp. brasiliensis; $16, P$. carotovorum subsp. carotovorum; 20, P. chrysanthemi IBSBF 920; 21, P. carotovorum subsp. brasiliensis Pcbr $212^{\mathrm{T}}$. B) oligonucleotídeos iniciadores desenvolvidos a partir da região IGS, específicos para $P$. carotovorum subsp. brasiliensis e algumas estirpes de $P$. carotovorum subsp. carotovorum. M, marcador $100 \mathrm{pb} ; 1-23, P$. carotovorum subsp. brasiliensis; 24, P. carotovorum subsp. atrosepticum $31 ; 25$, P. carotovorum subsp. brasiliensis Pcbr $212^{\mathrm{T}}$. C) oligonucleotídeos iniciadores específicos para $P$. carotovorum subsp. atrosepticum. M, marcador $1 \mathrm{~Kb}$ plus; 1 , P. carotovorum subsp. atrosepticum $31 ; 2$, P. carotovorum subsp. brasiliensis $\mathrm{Pcbr}$ $212^{\mathrm{T}}$; 3, P. carotovorum subsp. carotovorum IBSBF 1442; 4-21 e 23-24, P. carotovorum subsp. brasiliensis; 22 , P. carotovorum subsp. carotovorum; 25 , controle negativo (sem DNA).

\section{REFERÊNCIAS BIBLIOGRÁFICAS}

CAMPOS, E., MAHER, E.A. \& KELMAN, A. Relationship of pectolytic clostridia and Erwinia carotovora strains to decay of potato tubers in storage. Plant Disease 66:543-546. 1982.

COLMER, A. \& KEEN, N.T. The role of pectic enzymes in plant pathogenesis. Annual Review of Phytopathology 24:383-409. 1986. 
Ocorrência de pectobactérias em tubérculos de batata-semente no...

CUPPELS, D. \& KELMAN, A. Evaluation of selective media for isolation of soft rot bacteria from soil and plant tissue. Phytopathology 64:468-475. 1974.

DE BOER, S.H. \& KELMAN, A. Erwinia soft rot group. In: Schaad, N.W., Jones, J.B. \& Chun, W. (Eds.) Laboratory Guide for Identification of Plant Pathogenic Bacteria. $3^{\text {th }}$ ed. St. Paul. American Phytopathological Society. 2001. pp.56-72.

DE BOER, S.H. Relative incidence of Erwinia carotovora subsp. atroseptica in stolon end and peridermal tissue of potato tubers in Canada. Plant Disease 86:960-964. 2002.

DE BOER, S.H. \& WARD, L.J. PCR detection of Erwinia carotovora subsp. atroseptica associated with potato tissue. Phytopathology 5:854-858. 1995.

DUARTE, V., DE BOER, S.H., WARD, L.J. \& OLIVEIRA, A.M.R. Characterization of atypical Erwinia carotovora causing blackleg of potato in Brazil. Journal of Applied Microbiology 96:535-545. 2004.

DUARTE, V. \& EL TASSA, S.O.M. Taxonomia do gênero Pectobacterium. Revisão Anual de Patologia de Plantas 11:1-41. 2003.

DICKEY, R.S. \& KELMAN, A. Erwinia: "Carotovora" or soft rot group. In: Schaad, N.W. (Ed.) Laboratory Guide for Identification of Plant Patogenic Bacteria. 2 ed. St. Paul. American Phytopathological Society. 1988. pp.44-59.

ELPHINSTONE, J.G. Ecologia de espécies pectolíticas de Erwinia causantes de pudricion blanda y pierna negra de la papa. In: Lopes, C.A. \& Espinoza R.N. (Eds). Taller sobre enfermedades bacterianas de la papa. Brasília. EMBRAPA/CNPH. 1993. pp.59-66.

EPAGRI. Sistemas de produção para batata-consumo e batatasemente em Santa Catarina. 3 ed. Florianópolis. GMC/Epagri. 2002.

FESSEHAIE, A., DE BOER, S.H.\& LEVESQUE, C.A. Molecular characterization of DNA encoding 16S-23S RNA intergenic spacer regions and 16S rRNA of pectolytic Erwinia species. Canadian Journal of Microbiology 48:387-398. 2002.

FRÉCHON, D., EXBRAYAT, P., HELLAS, V., HYMAN, L.J., JOUAN, B., LLOP, P., LOPEZ, M.M., PAYET, N., PÉROMBELON, M.C.M., TOTH, I.K., VAN BECKHOVEN, R.C.M., VAN DER WOLF, J.M. \& BERTHEAU, Y. Evaluation of a PCR kit for the detection of Erwina carotovora subsp. atroseptica on potato tubers. Potato Research 41:163-173. 1998.

GOTO, M. \& MATSUMOTO, K. Erwinia carotovora subsp. wasabiae subsp. nov. isolated from diseased rhizomes and fibrous roots of japanese horseradish (Eutrema wasabi Maxim.). International Journal of Systematic Bacteriology 37:130-135. 1987. HYMAN, L.J., TOTH, I.K. \& PÉROMBELON, M.C.M. Isolation and identification. In: Pérombelon, M.C.M. \& Van Der Wolf, J.M. (Eds.). Methods for the detection and quantification of Erwinia carotovora subsp. atroseptica on potatoes. Laboratory Manual.
Invergowrie. Scottish Crop Research Institute. 1998. pp.60-65.

IBGE. Brasília, Instituto Brasileiro de Geografia e Estatística. Contém informações institucionais, técnicas, indicadores estatísticos, notícias, publicações e serviços. Disponível em: $<$ http:// www.ibge.gov.br>. Acesso em: 04 nov. 2003.

JABUONSKI, R.E., TAKATSU, A. \& REIFSCHNEIDER, F.J.B. Levantamento e identificação de espécies de Erwinia de diferentes plantas hospedeiras e regiões do Brasil. Fitopatologia Brasileira 11:185-195. 1986.

KELMAN, A. \& DICKEY, R.S. Detection of Erwinia carotovora and E. chrysanthemi. In: Saettler, A.W., Schaad, N.W. \& Roth, D.A. (Eds.) Detection of bacteria en seed and other planting material. St. Paul. American Phytopathological Society. 1989. pp.76-91.

LELLIOT, R.A. \& DICKEY, R.S. Genus VII. Erwinia Winslow, Brodahurst, Buchanan, Krumwiede, Rogers and Smith 1920. In: Krieg, N.R. \& Holt, J.G. (Eds.). Bergey's Manual of Systematic Bacteriology. Baltimore, Williams \& Wilkins. 1984. pp.469-476.

OLIVEIRA, A.M.R., DUARTE, V., SILVEIRA, J.R.P. \& MORAES, M.G. Incidence of pectolytic erwinias associated with blackleg of potato in Rio Grande do Sul. Fitopatologia Brasileira 28:49-53. 2003.

PÉROMBELON, M. \& KELMAN, A. Blackleg and other potato diseases caused by soft rot Erwinias: proposal for revision of terminology. Plant Disease 71:283-285. 1987.

PÉROMBELON, M. \& KELMAN, A. Ecology of the soft rot Erwinia. Annual Review of Phytopathology 12:361-387. 1980.

PIERCE, L. \& Mc CAIN, A.H. Selective medium for isolation of pectolytic Erwinia sp. Plant Disease 76:382-384. 1992.

PIRHONEN, M., SAARILAHTI, H., KARLSSON, M.B. \& PALVA, E.T. Identification of pathogenicity determinants of Erwinia carotovora subsp. carotovora by transposons mutagenesis. Molecular Plant-Microbe Interaction 4:276-283. 1991.

SALMOND, G.P.C. Secretion of extracellular virulence factors by plant pathogenic bacteria. Annual Review of Phytopathology 32:181200. 1994.

SILVEIRA, J.R.P., DUARTE, V. \& MORAES, M.G. Ocorrência das biovares 1 e 2 de Ralstonia solanacearum em lavouras de batata no Estado do Rio Grande do Sul. Fitopatologia Brasileira 27:450-453. 2002.

TAKATSU, A., MELLO, S. \& GARCIA, E.J. Fruto do pimentão como meio parcialmente seletivo para isolamento de Erwinia carotovora. Fitopatologia Brasileira 6:550-551. 1981.

THOMSON, S.V., HIDELBRAND, D.C. \& SCHROTH, M.N. Identification and nutritional differentiation of the Erwinia carotovora and Erwinia chrysanthemi. Phytopathology 71:10371042. 1981. 